\title{
La música patriótica en Valencia durante la Guerra de la Independencia española (1808-1814): mercado y repertorio
}

\author{
Patriotic Music in Valencia during \\ the Peninsular War (1808-1814): \\ Market and repertory
}

Este estudio muestra la evolución comercial, transmisión y modelos de la música de inspiración patriótica que se distribuyó en Valencia en la Guerra de la Independencia Española (18081814). Se aborda la identificación de diferentes obras relacionadas con este género, así como los establecimientos de venta que las anunciaron en la prensa local durante dicho periodo, confrontando la información obtenida con la referente a otros anuncios de lotes similares publicados en prensa foránea que pudieron haber comercializado material de características parecidas. También se ha planteado la correspondencia entre el volumen de anuncios y los acontecimientos bélicos que tuvieron eco en la vida de Valencia. Además, se identifica a dos copistas que ejercieron su labor en la ciudad, documentando algunas de sus transcripciones y composiciones conservadas en la Biblioteca Nacional de España. Por último, se ofrecen ejemplos de diferentes tipologías de este género musical que se han podido documentar en los periódicos valencianos.

Palabras clave: canción patriótica, himno, Valencia, Guerra de la Independencia, Fernando VII, guitarra, pianoforte.

This study discusses the evolution of trade, dissemination and types of music of patriotic inspiration distributed in Valencia during the Peninsular War (1808-1814). Different works related to this genre have been identified, as well as the sales outlets that advertised them in the local press during that period, comparing the information obtained with other foreign bookstore advertisements that sold similar music. Parallels between the volume of these advertisements and the warlike events that resonated in the life of Valencia have been found. In addition, two copyists who worked in the city have been identified. Some of their transcriptions and even compositions have also been documented in the National Library of Spain. Finally, examples of the different types of this musical genre that have been identified in Valencia are given.

Keywords: patriotic song, anthem, Valencia, Peninsular War, Ferdinand VII, guitar, pianoforte.

\section{Introducción}

El objetivo principal de este trabajo consiste en completar el panorama historiográfico musical valenciano del siglo XIX centrando la atención en el estudio de la literatura musical patriótica floreciente en esta ciudad en el 
periodo de la Guerra de la Independencia (1808-1814). Para ello, se pretende analizar la distribución comercial de partituras, identificar, clasificar y relacionar las diferentes obras con ejemplares conservados o documentados en diversos estudios, catálogos y fondos ${ }^{1}$. Asimismo, el artículo aspira a establecer paralelismos y divergencias comparando las características de la evolución del mercado local, el volumen de ventas y la tipología de las obras con los de otras ciudades españolas estudiadas hasta el momento, comprobando la relación entre la actividad comercial y los diversos acontecimientos bélicos que vivió la ciudad. También se intentan documentar algunos de los copistas y músicos que trabajaron en la transmisión manuscrita y composición de este tipo de literatura, mostrando ejemplos recuperados e identificados de su trabajo. En concreto, se expone la figura del presbítero beneficiado y profesor Francisco Ximeno, en el ámbito privado de la docencia a la nobleza, y la del cantante y pianista Josef Francisco Acuña, compositor y copista en al menos dos librerías. Para ello se han examinado y clasificado sistemáticamente fuentes hemerográficas locales y foráneas del periodo. Asimismo, se han revisado e identificado las piezas, relacionándolas con otras ofrecidas en anuncios de la prensa y fuentes documentales de otras ciudades productoras de esta literatura, como Madrid, Sevilla o Cádiz. Los principales vaciados de noticias musicales en prensa no abarcan la etapa estudiada ${ }^{2}$. Sin embargo, existe un extenso corpus de literatura científica en torno a la música de inspiración patriótica ${ }^{3}$, militar $^{4}$, de

${ }^{1}$ Como los de la Biblioteca Nacional de España (E-Mn); la colección de la Biblioteca del Senado (E-Ms); el Fondo Borbone de la Biblioteca Palatina de Parma, estudiado por Lluís Bertran, Ana Lombardía, Judith Ortega: "La colección de manuscritos musicales españoles de los Reyes de Etruria en la Biblioteca Palatina de Parma (1794-1824): un estudio de fuentes", Revista de Musicología, 38, 1, 2015 , pp. 107-190; la "Colección Documental del Fraile", estudiada por Ana María Freire: Índice Bibliográfico de la Colección Documental del Fraile, Madrid, Ministerio de Defensa, 2008; la colección reunida por Francesc Cortès, Josep-Joaquim Esteve: Músicas en tiempos de guerra. Cancionero (1503-1939), Barcelona, Servei de Publicacions de la Universitat Autònoma de Barcelona, 2012; el catálogo de Juan Bautista Escribano Sierra, Cayetano Hernández Muñiz, José María Soto de Lanuza: Guerra y revolución: música española 1788-1833, Madrid, Biblioteca Nacional de España, 2006, NIPO 032-13-025-1, y la monumental obra de Brian Jeffery: España de la guerra: The Spanish Political and Military Songs of the War in Spain, 1808-1814, Londres, Tecla editions, 2017, entre otros.

2 Yolanda Acker: Música y danza en el "Diario de Madrid". Noticias, avisos y artículos, 1758-1808, Madrid, Centro de Documentación de Música y Danza-INAEM, 2007; Manuel Sancho García: "Fuentes para el estudio de la música en Valencia: el 'Diario de Valencia' (1790-1808)", Archivo de Arte Valenciano, 97, 2016, pp. 233-248 (https://hdl.handle.net/10550/74287, consulta 26-10-2020).

${ }^{3}$ María Gembero-Ustárroz: "La música en España e Hispanoamérica durante la ocupación napoleónica (1808-1814)", Cortes y revolución en el primer liberalismo español. Actas de las sextas jornadas sobre la Batalla de Bailén y la España Contemporánea, Francisco Acosta (ed.), Jaén, Universidad de Jaén, 2006, pp. 171-231; Paulino Capdepón Verdú: "La música madrileña durante la Guerra de la Independencia: la canción patriótica", Anales del Instituto de Estudios Madrileños, 48, 2008, pp. 131-148.

${ }^{4}$ Ricardo Fernández de Latorre: Historia de la música militar de España, Madrid, Ministerio de Defensa, 2014. 
inspiración revolucionaria ${ }^{5}$, y también trabajos que resaltan la profunda influencia política ${ }^{6}$ que tuvo en los distintos centros productores y receptores de esta literatura ${ }^{7}$. Todo ello permite documentar y relacionar las obras ofrecidas en Valencia con el contexto creativo, productor y comercial español.

Con relación al escenario geopolítico en el que se enmarca el estudio cabe decir que Valencia, una de las tres ciudades con mayor población de España al comienzo del siglo XIX, se sublevó contra Napoleón y José I en mayo de 1808, tras la lectura pública de las abdicaciones de Bayona de Carlos IV y Fernando $\mathrm{VII}^{8}$. La ciudad se unía así a los levantamientos que tenían lugar a lo largo del territorio peninsular, producidos por la deserción en masa de gran parte de la cadena de mando del ejército español, que renunciaba a asistir militarmente al ejército francés presente en la península. Se iniciaba de este modo la Guerra de la Independencia Española, que enfrentó la población autóctona al ejército francés, pero también las diferentes sensibilidades de afrancesados, realistas y liberales?.

${ }^{5}$ María Gembero-Ustárroz: "Reflejos de la música revolucionaria francesa en la España napoleónica (1808-1814): cantos y propaganda política en calles y salones”, Cuadernos de Música Iberoamericana, 25-26, 2013, pp. 143-160 (https://revistas.ucm.es/index.php/CMIB/article/view/58954, consulta 10-92020).

${ }^{6}$ Begoña Lolo: "La música al servicio de la política en la Guerra de la Independencia", Cuadernos Dieciochistas, 8, 2007, pp. 223-245; Marieta Cantos Casenave: "La conjura de Orfeo. Música en tiempos de guerra (1808-1814)", España Contemporánea: Revista de Literatura y Cultura, 21, 2, 2008, pp. 67-80; Ana María Freire López: "Estrategias teatrales frente a la invasión francesa (1808-1814). El teatro patriótico durante la Guerra de la Independencia”, Cuadernos de Ilustración y Romanticismo, 19, 2013, pp. 163172 (https://doi.org/10.25267/Cuad_Ilus_Romant.2013.i19.10, consulta 26-10-2020), entre otras.

${ }^{7}$ Oriol Brugarolas Bonet: "El comercio de partituras en Barcelona entre 1792 y 1834: de Antonio Chueca a Francisco Bernareggi", Anuario Musical, 71, 2016, pp. 163-178 (https://doi.org/10.3989/ anuariomusical.2016.71.09, consulta 10-9-2020); Cristina Díez: "Teatro, canciones e himnos patrióticos: la música al servicio de los ideales políticos en el Cádiz de las Cortes”, Cuadernos de Música Iberoamericana, 18, pp. 7-36 (https://revistas.ucm.es/index.php/CMIB/article/view/61129, consulta 10-9-2020); Virginia Sánchez López: "España de la guerra (1808): la difusión internacional del cancionero de la Guerra de la Independencia", Cuadernos de Música Iberoamericana, 23, 2012, pp. 23-36 (https://revistas.ucm.es/index.php/CMIB/article/view/59443, consulta 10-9-2020); Virginia Sánchez López: "La música en Andalucía durante la Guerra de la Independencia (1808-1814)", Andalucía en guerra (1808-1814), José Miguel Delgado Barrado (ed.), María Amparo López Arandia (coord.), Jaén, Universidad de Jaén, 2010, pp. 299-308; María Gembero-Ustárroz: "El ambiente musical en el Cádiz de las Cortes: un himno de Manuel Rücker para celebrar el regreso a España de Fernando VII (1814)", Ocio y vida doméstica en el Cádiz de las Cortes, Alberto Ramos (coord.), Cádiz, Diputación de Cádiz, 2012, pp. 73-132; María José de la Torre Molina: La música en Málaga durante la Era Napoleónica (1808-1814), Málaga, Universidad de Málaga-Ayuntamiento de Málaga, 2003; María José de la Torre Molina: "Música, poder y propaganda en las honras malagueñas por los héroes de Bailén (1808)", Boletín de Arte, 29, Málaga, 2008, pp. 215-237 (https://doi.org/10.24310/BoLArte.2008.v0i29.4430, consulta 10-9-2020), entre otras.

${ }^{8}$ Difundidas en la Gazeta de Madrid, n. ${ }^{\circ} 48,20-5-1808$, pp. 482-484.

${ }^{9}$ M. Gembero-Ustárroz: "Reflejos de la música...", p. 145. 
La población de Valencia resistió sendos asedios en 1808 y 1810, aunque se rindió ante el mariscal Suchet en enero de 1812, acogiendo después a José I y su corte durante casi siete semanas. En julio de 1813 fue ocupada por el general Villacampa, convirtiéndose en abril de 1814 en el escenario del retorno triunfal y el golpe de estado encubierto de FernandoVII ${ }^{10}$. En este periodo, las librerías de la ciudad pusieron a la venta un considerable volumen de canciones de influencia patriótica que fueron probablemente consumidas en todo tipo de eventos de la sociedad valenciana: desde las tertulias de la alta sociedad hasta los festejos improvisados en tabernas y posadas (ilustración 1).

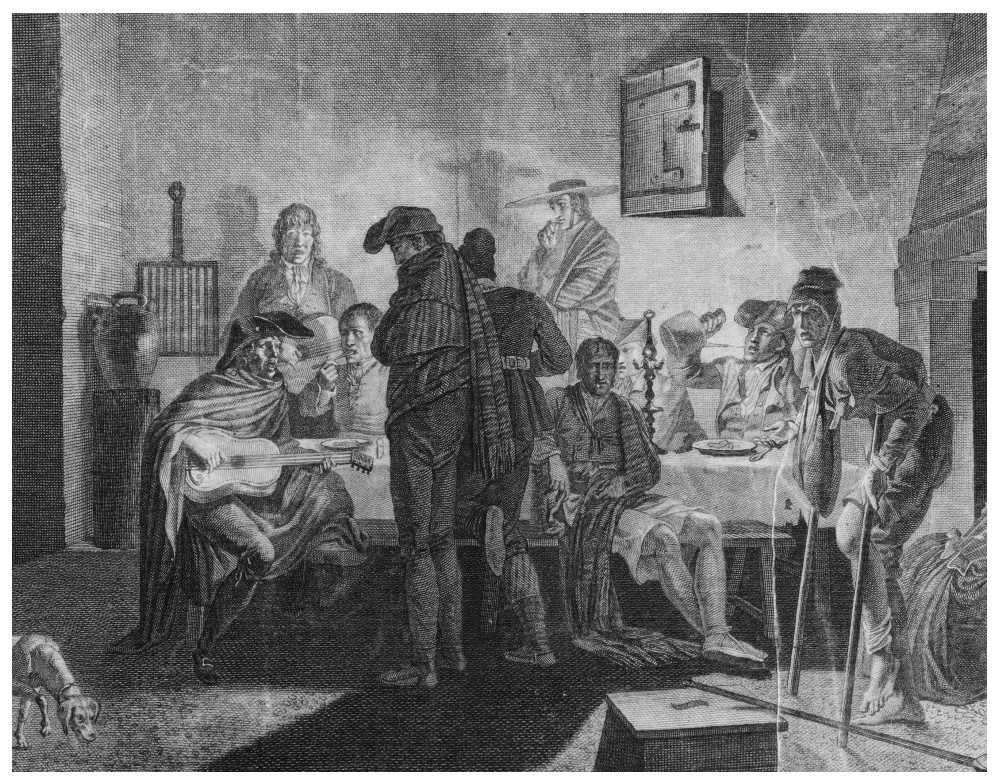

Ilustración 1. Dutailly (dibujo); Robert Delaunay (grabado):Vista interior de una posada en el Reino de Valencia, para el Voyage pittoresque et historique de l'Espagne de Alexandre de Laborde (ca. 1811), en el que se aprecia una escena costumbrista con dos sujetos cantando a la guitarra (BNE)

\section{El tejido cultural al servicio de la propaganda ideológica: la música patriótica en Valencia}

En líneas generales, la difusión de ideales patrióticos como herramienta para la subversión popular frente a la ocupación francesa en la Guerra de la Independencia impregnó varias esferas de la vida cultural española, en las que

${ }^{10}$ Manuel Sanchis Guarner: La ciudad de Valencia: síntesis de historia y geografía urbana, Valencia, IRTA, 1972, pp. 272 y ss. Sobre el golpe de estado de Fernando VII, véase Emilio La Parra: Fernando VII. Un rey deseado y detestado, Barcelona, Tusquets, 2018, pp. 224-278. 
la música jugó un papel clave ${ }^{11}$. Para ello fue primordial la utilización de la prensa. La hegemonía de las publicaciones antifrancesas ${ }^{12}$ permitió una eficiente distribución, no solamente de noticias sobre batallas y movimientos de tropas, sino de soflamas, artículos, himnos, canciones y todo tipo de literatura destinada a conmover políticamente a la sociedad ${ }^{13}$. Además de esto, uno de los primeros vehículos de propagación de los primeros cantos fue el ejército, que los utilizó en sus entradas triunfales o actos multitudinarios. Sirvan como ejemplo las coplas del Himno de la Victoria, también conocido como Himno de las provincias ("Venid vencedores") ${ }^{14}$, que el poeta Juan Bautista Arriaza (1770-1837) preparó en pocos días para que fueran cantadas a la entrada en Madrid de las tropas liberadoras de Bailén al mando del general Castaños (julio de 1808) ${ }^{15}$.

El teatro fue otro de los ejes principales de la propaganda en los territorios sublevados: los principales coliseos de la península cerraron o disminuyeron su actividad al principio de la contienda por la actitud desfavorable de juntas y cabildos $^{16}$, pero fueron cediendo a la presión pública para ofrecer la representación de obras alegóricas, soliloquios, tonadillas, himnos y canciones patrióticas alusivas al conflicto ${ }^{17}$. Al contrario que en otras ciudades, como Cádiz ${ }^{18}$, en Valencia el teatro no volvió a abrir sus puertas hasta febrero de 1812, mes en el que, rendida la ciudad, el nuevo gobierno francés reanudó la actividad cultural oficial ${ }^{19}$. Esta carencia se subsanó con la intensificación de la exaltación ideoló-

${ }^{11}$ B. Lolo: "La música al servicio...", pp. 223-245.

12 Únicamente un ocho por ciento de la prensa era proclive al bando francés. Antonio Checa Godoy: "La prensa napoleónica en España (1808-1814). Una perspectiva", El Argonauta Español [en línea], 10, 2010 (https://doi.org/10.4000/argonauta.1848, consulta 26-10-2020).

13 Vicente León Navarro: "Papel y poder de la prensa en la Guerra de la Independencia (18081809). El caso valenciano", El Argonauta Español, 7, 2010 (https://doi.org/10.4000/argonauta.436, consulta 07-7-2020); Vicente León Navarro: "La prensa valenciana ante la Guerra del Francés en 1808", El Argonauta Español, 5, 2008 (https://doi.org/10.4000/argonauta.908, consulta 6-7-2020).

${ }^{14}$ B. Lolo: "La música al servicio...", pp. 227-228.

15 Aunque esta afirmación es la que la historiografía ha recogido tradicionalmente, al menos con respecto a las primeras coplas, existe cierta controversia sobre si el texto de Arriaza se pudo cantar realmente en la entrada del ejército junto a las músicas militares o si se difundió en celebraciones y teatros en aquellos días. Véase B. Jeffery: España de la guerra..., pp. 95-99.

${ }^{16}$ Véase el caso de Madrid en M. ${ }^{\text {a }}$ Mercedes Romero Peña: El teatro en Madrid durante la Guerra de la Independencia 1808-1814, Madrid, Fundación Universitaria Española, 2006, citado en B. Lolo: "La música al servicio...", p. 225. Sevilla y Málaga también tuvieron problemas para representar obras entre 1808 y 1810, antes de su ocupación. Véase M. Gembero-Ustárroz: "La música en España e Hispanoamérica...", pp. 203-204, y V. Sánchez López: "La música en Andalucía...", p. 301.

${ }^{17}$ Sobre reflejos y antecedentes en la tonadilla escénica de tema militar del s. XVIII español véase R. Fernández de Latorre: Historia de la música militar..., pp. 109-115.

${ }^{18}$ C. Díez: "Teatro, canciones e himnos...", pp. 7-36.

19 Se encomendó la nueva dirección del teatro al actor Jaime Montaña. En el aspecto musical se confió en los músicos locales Blas Vicente y Josef Valero, probable progenitor del célebre músico José Valero Peris. Diario de Valencia, 16-2-1812 [sin n. ${ }^{\circ}$ de p.] 
gica en otros ámbitos, como demuestran las numerosas rogativas y ceremonias públicas ${ }^{20}$. También son representativos los textos de los villancicos que compuso el maestro de capilla de la catedral, Josep Pons $(1768-1818)^{21}$ en los años 1808 y 1809 -reutilizados de forma reveladora en 1813, firmado ya el tratado deValençay ${ }^{22}$.A estos aspectos se les unió la aparición de numerosos panfletos, poesías, proclamas y disertaciones políticas que usaron la prensa como medio de difusión ${ }^{23}$, así como la venta de lotes de himnos y canciones patrióticas, al igual que ocurrió en Cádiz durante los meses que el teatro estuvo cerrado ${ }^{24}$. En este sentido, cabe destacar la impresión en la propia ciudad de obras dramáticas alegóricas de reducidas dimensiones, como la pieza España encadenada por la perfidia francesa y libertada por el valor de sus hijos ${ }^{25}$, referida como ejemplo por Ana María Freire en relación con las características del teatro patriótico de los primeros años de la guerra ${ }^{26}$. Su subtítulo, "pieza fácil de representar en cualquiera casa por constar de solas cinco personas", parece confirmar el intento de suplir la carencia de un espacio escénico en activo y reproducir en la ciudad una literatura funcional fácil de ser representada en ámbitos domésticos.

Es desde estos ámbitos, el teatral y el doméstico, donde se desarrolló el principal género de la literatura musical de esta etapa: la música patriótica. En contraposición a los himnos cantados a coro por actores y público exaltado en los coliseos, las canciones ejecutadas por solistas no funcionaban bien en los grandes espacios, pero sí en el ambiente privado y familiar ${ }^{27}$. Así pues, desde la

\footnotetext{
${ }^{20}$ Véase, como ejemplos, Vicente Martínez Colomer: Sucesos de Valencia, desde el día 23 de mayo hasta el 28 de junio del año 1808, Valencia, Salvador Faulí, 1810, pp. 26-27 y [Junta Superior de Gobierno de Valencia]: La ciudad de Valencia renueva la memoria de la exaltación al trono del Señor D. Fernando VII y ofrece al público la estatua de S. M. Valencia, imprenta del Diario, 1809 (https://bivaldi.gva.es/es/ consulta/registro. do?id=1702, consulta 31-12-2019).

${ }^{21}$ Analizados por Ignacio Prats: "'La verdadera libertad del género humano': villancicos de Navidad durante la Guerra de Independencia en la Catedral de Valencia", La catedral ilustrada. Iglesia, sociedad y cultura en la Valencia del siglo XVIII, vol. 4, Emilio Callado Estela (ed.), Valencia, Institució Alfons el Magnànim, 2017, pp. 373-412.

${ }^{22}$ E-Mn: R/34991/9 (http://bdh.bne.es/bnesearch/detalle/bdh0000106240, consulta 27-10-2020). Resulta interesante relacionarlos con los "cánticos patrióticos" interpretados por la misma capilla de la catedral dirigida por Pons en la serenata nocturna que presidió Fernando VII a su llegada en 1814, en un contexto antiliberal de exaltación del monarca absoluto. Véase Juan Facundo Sidro Villaroig: Memoria de los regocijos públicos que en obsequio del Rey Fernando VII dispuso la ciudad de Valencia, Valencia, Monfort, 1814, pp. 69, 98, 112 (https://bivaldi.gva.es/es/consulta/registro.do?id=1798, consulta 20-11-2019).

${ }^{23}$ Véanse como ejemplos las obras conservadas y reproducidas en la Biblioteca Valenciana Digital-Bivaldi bajo la materia "España-Historia-1808-1814 (Guerra de la Independencia)" y en la Biblioteca Histórica de la Universitat de València bajo la materia "Comunitat Valenciana-Història-1808-1814, Invasió napoleónica".

${ }^{24}$ C. Díez: "Teatro, canciones e himnos...", p. 27.

${ }^{25}$ España encadenada por la perfidia francesa; y libertada por el valor de sus hijos: pieza fácil de representar en cualquiera casa por constar de solas cinco personas, Valencia, Miguel Estevan y Cervera, ca. 1809 (https://bivaldi.gva.es/va/consulta/registro.do?id=3227, consulta 2-7-2020).

${ }^{26}$ A. M. Freire López: "Estrategias teatrales...", pp. 166 y ss.

${ }^{27}$ C. Díez: "Teatro, canciones e himnos...", pp. 14-15.
} 
canción lírica con acompañamiento de pianoforte o guitarra, como el predominante en el mercado de partituras valenciano anterior a marzo de 1808, se adaptaron las diversas piezas cantadas en los ambientes públicos hacia una épica doméstica que dominó en tabernas, tertulias y reuniones privadas a lo largo de toda la España sublevada ${ }^{28}$. Esta gran producción de himnos, marchas y canciones fue empleada también con "fines propagandísticos", para así "estimular el patriotismo, aunar los esfuerzos contra el enemigo, en fin sumar a todos los españoles en un proyecto común" 29 . Igualmente, sirvió para propagar durante el conflicto noticias de victorias y batallas, siendo consumida por gran parte de la población española contraria al bando francés, tal y como se desprende de los testimonios de Alcalá Galiano (1789-1865), Mesonero Romanos (1803$1882)^{30}$ o el compositor Joaquín Tadeo de Murguía (1759-1836) ${ }^{31}$.

Para la música de estas obras se solía utilizar melodías populares (seguidillas, polos, tiranas, cachuchas, fandangos, zorongos o jotas) o de la esfera lírica ${ }^{32}$. A ellas se les aplicaban las letras, muchas veces utilizando la técnica de los contrafacta (uso de textos intercambiables en melodías preexistentes), lo que permitía una popularización inmediata a pesar de ofrecer contenido muchas veces de signo ideológico contrario al de las canciones originales ${ }^{33}$. Asimismo, las canciones compartían algunas características comunes, como una estructura tripartita, forma alternada de estrofas y estribillo ${ }^{34}$, así como melodías de carácter silábico con intervalos melódicos iniciales característicos (cuarta justa, sexta mayor), debido al uso de las notas del acorde mayor como motivo temático.

En otras ocasiones, la colaboración entre poetas y músicos de renombre generaba piezas de una mayor calidad musical y estilística ${ }^{35}$. Fernando Sor $(1778-1839)^{36}$, Mariano Rodríguez de Ledesma (1779-1847) $)^{37}$

${ }^{28}$ M. Gembero-Ustárroz: "La música en España e Hispanoamérica...", p. 179; C. Díez: "Teatro, canciones e himnos...", p. 27.

${ }^{29}$ M. Cantos Casenave: "La conjura de Orfeo...", p. 70.

${ }^{30}$ B. Lolo: "La música al servicio...", p. 226.

${ }^{31}$ El compositor Joaquín Tadeo de Murguía era autor del revelador panfleto La música considerada como uno de los medios más eficaces para excitar el patriotismo y el valor (E-Mn: R/60823). Lothar Siemens Hernández: "Joaquín Tadeo de Murguía. Propulsor de la música patriótica durante la invasión napoleónica", Revista de Musicología, V, 1982, pp. 163-166; Juan Bautista Escribano Sierra: "Diario musical de una época", Guerra y Revolución..., p. 27.

${ }_{32}$ M. Gembero-Ustárroz: "La música en España e Hispanoamérica...", pp. 243-244; V. Sánchez López: "La música en Andalucía...", p. 300.

${ }^{33}$ F. Cortès, J.-J. Esteve: Músicas en tiempos de guerra..., p. 72; M. Gembero-Ustárroz: "Reflejos de la música...", p. 148.

${ }^{34}$ B. Lolo: "La música al servicio...", p. 230.

35 José María Soto de Lanuza, "La música y el acontecimiento histórico", Guerra y Revolución..., pp. 16-17; J. B. Escribano Sierra, "Diario musical...", pp. 25 y ss.

${ }^{36}$ Luis Gásser (ed.): Estudios sobre Fernando Sor / Sor Studies, Madrid, ICCMU, 2003; Brian Jeffery: Fernando Sor, Composer and Guitarist, Tecla Editions, 1994.

${ }^{37}$ Tomás Garrido: Mariano Rodríguez de Ledesma (1779-1847): vida y obra de un músico del Romanticismo, tesis doctoral, Universidad Complutense de Madrid, 2019. 
destacaron junto con Benito Pérez, Francisco José de Molle o Joaquín Tadeo de Murguía, entre otros, en la composición de la música de las canciones más célebres ${ }^{38}$.

En los territorios sublevados, las librerías se adhirieron al fervor productivo, ofreciendo lotes de este tipo de partituras en las que solía primar la funcionalidad a la calidad estética ${ }^{39}$. El acompañamiento musical era adaptado a la guitarra o al pianoforte por copistas profesionales con el fin de satisfacer la demanda de los compradores. Los títulos solían ser descriptivos ${ }^{40}$ y en ocasiones divergentes, dependiendo del anuncio y el lugar de venta, utilizando adjetivaciones y epítetos diversos como reclamo publicitario ${ }^{41}$.

Un ejemplo muy interesante para comprobar la funcionalidad e influencia de este tipo de literatura musical lo constituye la partitura transcrita en Valencia en 1810 de la Canción de los defensores de la Patria ("Vivir en cadenas"), compuesta por Fernando Sor con letra de Juan Bautista Arriaza, que he podido localizar y documentar en la Biblioteca Nacional de España ${ }^{42}$. Dicha obra, transcrita por el desconocido copista privado y profesor de canto y pianoforte Francisco Ximeno (1763-1829) ${ }^{43}$, fue "acomodada", tal y como reza su título, para que su discípula Pascuala de Pedro y Llorens (1785$1827)^{44}$, baronesa de Otos ${ }^{45}$, pudiera ejecutarla al piano (ilustración 2$)^{46}$. Esta transcripción demuestra la aceptación y uso de la música patriótica no únicamente en ambientes populares, sino en reuniones de las clases más pudientes de la sociedad valenciana.

38 V. Sánchez López: "La música en Andalucía...", p. 300; B. Lolo: "La música al servicio ...", pp. 228-230.

${ }^{39}$ M. Gembero-Ustárroz: "La música en España e Hispanoamérica...", p. 182.

${ }^{40}$ Muchas veces con una función informativa, como un "rápido medio de difusión de las noticias que se estaban produciendo". B. Lolo: "La música al servicio...”, p. 230.

${ }^{41}$ L. Bertran, A. Lombardía, J. Ortega: "La colección de manuscritos...”, p. 146-160.

${ }^{42}$ E-Mn: MP/3183/5. Consta de una hoja apaisada exenta de 12 pentagramas utilizada por ambas caras que lleva escrito en su cabecera: "Canción de los defensores de la Patria / acomodada a piano solo por Ximeno en Valencia año de 1810 / y transportada pa. el uso de su Disipula [sic.] D. . Pasquala de Pedro".

${ }^{43}$ Francisco Ximeno era beneficiado de muceta en el coro catedralicio y propietario de un Quaderno de Mucica [Música] pa Pianoforte (1805) que constituye una de las primeras compilaciones confeccionadas para el estudio específico del piano en Valencia. José Gabriel Guaita Gabaldón: "El Cuaderno de música para pianoforte de Francisco Ximeno (Valencia, 1805): estudio biográfico y técnico", tesis de máster, Universidad Politécnica de Valencia, 2019 (http://hdl.handle.net/10251/129943, consulta 109-2020).

${ }^{44}$ Sus fechas de nacimiento (17-5-1785) y muerte, desconocidas hasta ahora, han sido deducidas de la inscripción de su lápida sepulcral, donde figura que murió a los 42 años y ocho días de edad el 26-5-1827. Cementerio General de Valencia: nicho 102, sección 1. a .

${ }^{45}$ Era hija de Rafael de Pedro y Trullench, caballero de la Real Maestranza de Valencia, y de Joaquina Llorens y Núñez, marquesa de Benemejís de Sistallo. Asimismo, era hermana de Joaquín de Pedro y Llorens (1777-1857), marqués de San José, Albaida y Benemejís de Sistallo y héroe del "Sitio de Valencia" en 1808.

${ }^{46}$ Básicamente, aunque posee algunas desviaciones melódicas sobre los textos originales, fue transportada desde la tonalidad original de Sib mayor a Do mayor. 


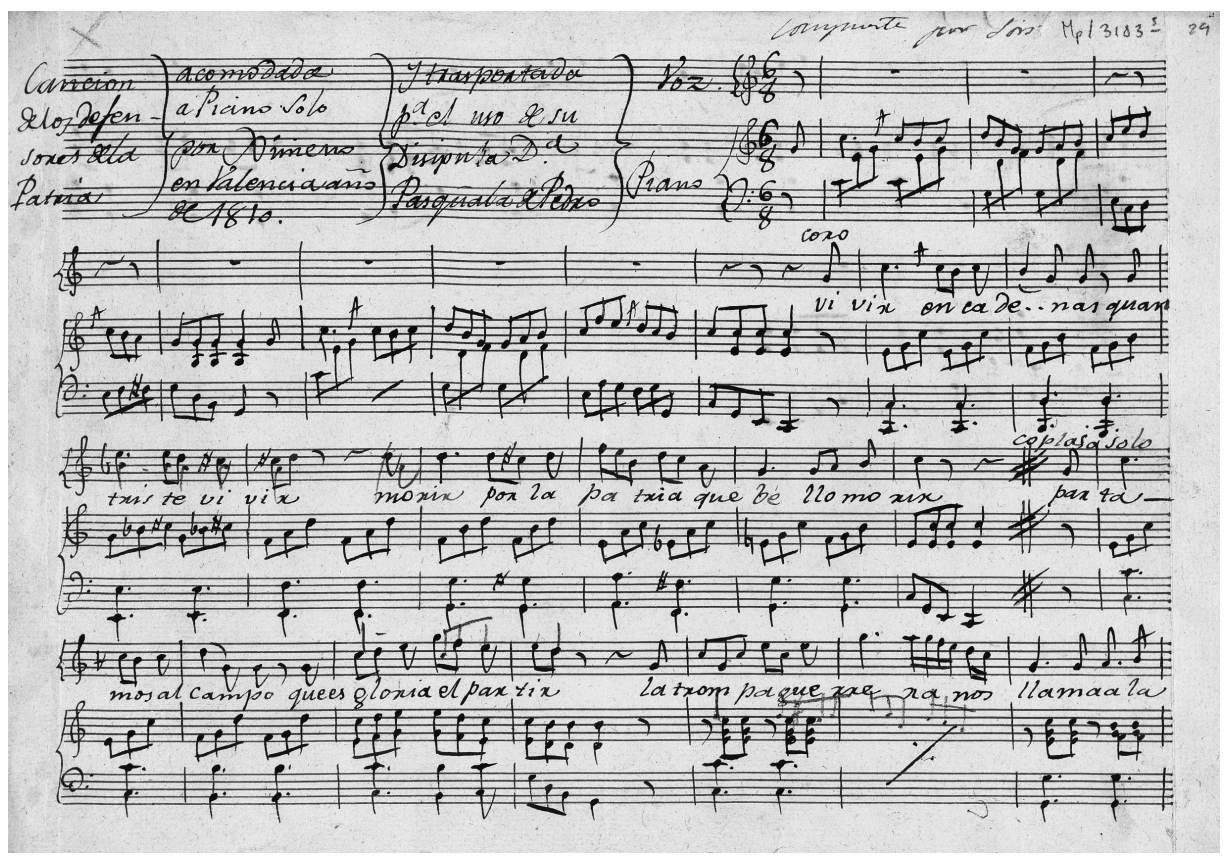

Ilustración 2. Primera página de la partitura Los Defensores de la Patria, adaptada por Francisco Ximeno en Valencia en 1810 de la original de Fernando Sor, E-Mn: MP/3183/5 (BNE)

\section{Evolución del comercio y difusión de música patriótica: relación con los acontecimientos bélicos y políticos acaecidos en la ciudad. Copistas}

Respecto a la difusión y comercio de la música patriótica, la prensa, utilizada para favorecer el comercio de literatura musical, constituye una fuente valiosa de información sobre la recepción y distribución de estas obras en el periodo estudiado. De hecho, gracias a la consulta exhaustiva de fuentes hemerográficas he podido documentar la primera librería local conocida que vendió partituras escritas con la indicación "para pianoforte" en Valencia ${ }^{47}$ : la de Bernardo Francés, sita en la calle de Zaragoza, que anunciaba las Seis Sonatas orgánicas para pianoforte ó clave, con acompañamiento de un violín ó sin él de Vicente Castillón en la prensa madrileña en $1781^{48}$.

Con la aparición de la prensa local, el Diario de Valencia (1790) y la Gazeta de Valencia (1808), se potenció la publicidad de particulares, almacenes y librerías dentro de la ciudad. Entre 1790 y 1808, el mercado había ofrecido

${ }^{47}$ El piano en Valencia ha sido estudiado ampliamente por Victoria Alemany Ferrer: El piano en Valencia en los años del cambio al siglo XX (1879-1916), Monumentos de la Música Española LXXIX, Barcelona, CSIC, 2010.

${ }^{48}$ Gazeta de Madrid, n. ${ }^{\circ} 83,16-10-1781$, p. 824. 
de forma puntual diversas obras dedicadas al pianoforte y al violín, las cuales eran distribuidas por las grandes librerías de la ciudad ${ }^{49}$. A partir de la victoria en el primer asedio francés en 1808, las librerías de Manuel López ${ }^{50}$, en la plaza del colegio del Corpus Christi, el almacén de la calle de Gracia, n. ${ }^{\circ} 24$, y el recién inaugurado establecimiento de Mariano Cabrerizo, también en la plaza del colegio del Corpus Christi, coparon los anuncios de partituras durante los dos primeros años de contienda (1808-1809) ${ }^{51}$. Estas casas ofrecían lotes de obras muy similares a los que se producían y anunciaban en las librerías de Madrid, cuestión importante para plantear la existencia de una posible ruta de distribución desde la capital en los primeros dos años. Otras grandes firmas como Mallén, los hermanos Faulí y Minguet se incorporarían después, en 1810, año de máxima publicidad de música patriótica, posiblemente consecuencia directa del fracaso francés en el segundo asedio de Valencia. Las obras, que se distribuían manuscritas y por encargo, se arreglaban bajo petición: diversos copistas adaptaban el acompañamiento de las piezas más célebres para piano y guitarra, atendiendo a las preferencias de cada cliente y adecuándolas a su instrumento y al medio social en el que se desenvolvía. A finales de 1811, los anuncios disminuyeron drásticamente, de acuerdo con el desánimo que cundía en la población ante los fracasos bélicos, la carestía y la proximidad del enemigo. En enero de 1812, con la ocupación francesa de la ciudad, cesó el comercio y distribución de este tipo de piezas. Tampoco constan anuncios de canciones del bando afrancesado. Posteriormente, la retirada francesa en 1813 y la entrada triunfal de Fernando VII en 1814 impulsaron de nuevo cierto comercio local de esta música, aunque no alcanzó el volumen de anuncios de los años anteriores (véase gráfico 1). A las canciones patrióticas se les sumaron otras con expreso contenido político liberal, constatando el emergente descontento que provocó el giro hacia el absolutismo del monarca ${ }^{52}$. A continuación, se explicitan los principales datos de cada uno de los establecimientos, obras anunciadas identificadas, relaciones con otros lotes y anuncios foráneos, así como ejemplares conservados de las mismas en diferentes fondos.

\footnotetext{
${ }^{49}$ M. Sancho: "Fuentes para el estudio ...", p. 246.

${ }^{50}$ Manuel López y Gimeno (fl. 1808-1848). Su catálogo de 1806 recoge 170 registros que atestiguan la producción de 269 ejemplares y un volumen de facturación modesto. Genaro Lamarca Langa: "Las librerías en Valencia en la segunda mitad del siglo XVIII", Bulletin Hispanique, 99, 1, 1997, pp. 182 y 189 (https://doi.org/10.3406/hispa.1997.4932, consulta 10-9-2020).

${ }^{51}$ Manuel López solamente ofreció canciones populares y adaptaciones de arias de ópera sin contenido patriótico ni político hasta 1814 .

${ }^{52}$ Como ejemplo, en el mismo número del diario y a la venta desde su imprenta y puestos se llegaron a anunciar dos textos pertenecientes a cada uno de los bandos, titulados como "coplas patrióticas del día": La Cachuchita, del bando realista, y la polémica canción liberal Marica Constitucional. Diario de Valencia, n. ${ }^{\circ} 82,22-3-1814$, p. 618.
} 


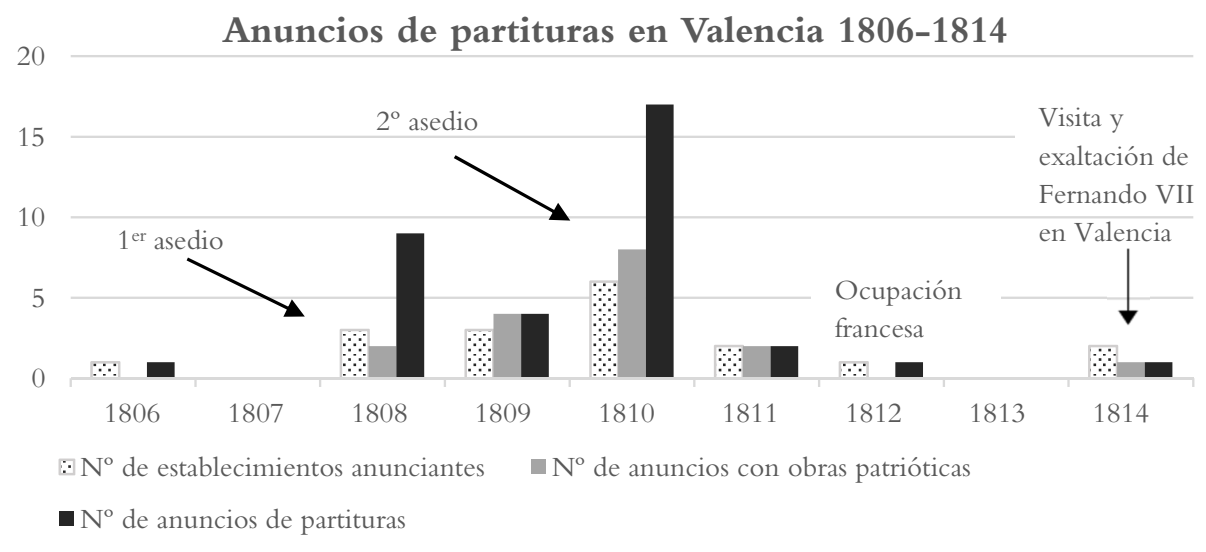

Gráfico 1. Evolución de los anuncios de venta de partituras en Valencia (1806-1814)

Los primeros anuncios con música patriótica los publicitó un almacén situado en la primera habitación del número 24 de la calle de Gracia ${ }^{53}$ entre noviembre de 1808 y febrero de $1809^{54}$. Parece que dicho establecimiento podría constituir la tentativa de algún agente o librería foránea por instalarse en la ciudad, pero dado que no volvió a insertar anuncio alguno a partir de febrero de 1809 (tres meses después), posiblemente cambiara de ubicación o desistiera en su empeño de establecerse en Valencia. Cabe la posibilidad de que el "almacenista" anónimo de partituras fuera el librero Mariano Cabrerizo (17851868), siendo esta la primera ubicación de su establecimiento, o bien que se tratase de la "casa de comercio" donde trabajó, tal como refiere en sus memorias $^{55}$. En apoyo de esta tesis cabe decir que los primeros anuncios firmados por Cabrerizo datan de marzo del mismo año (1809) y algunas de sus primeras canciones a la venta, en noviembre, coinciden con las que vendía dicho almacén (cf. cuadros 1 y 3 ).

\footnotetext{
${ }^{53}$ El almacén en cuestión estaba situado en la manzana 407, a espaldas del convento de San Gregorio, al lado del carpintero Mariano Vila, clavario del gremio de carpinteros en 1807 y afamado constructor de salterios. Valencia, Archivo del Reino (E-VAar), Gremios, libro 423.

${ }^{54}$ Dos en el Diario de Valencia, n. ${ }^{\circ} 64,04-12-1808$, p. 260; n. ${ }^{\circ} 51,20-2-1809$, p. 204; y dos en la Gazeta de Valencia, n. ${ }^{\circ}$ 55, 29-11-1808, p. 628; n. ${ }^{\circ}$ 57, 6-12-1808, p. 652, de reciente aparición.

${ }_{55}$ Mariano Cabrerizo y Bacuas: Memorias de mis vicisitudes politicas, Valencia, Ferrer y Aisa, 1862, p. XIV; José Enrique Serrano Morales: Reseña histórica en forma de diccionario de las imprentas que han existido en Valencia desde la introducción del arte tipográfico en España hasta el año 1868: con noticias bio-bibliográficas de los principales impresores, Valencia, Doménech, 1898-99, pp. 64 y ss. (http://bdh.bne.es/ bnesearch/detalle/bdh0000147787, consulta 13-10-2019).
} 
Cuadro 1. Anuncios de música patriótica desde el almacén de la calle de Gracia, $n .^{\circ} 24$ (1808-1809)

\begin{tabular}{|c|c|c|c|c|}
\hline Títulos & Autor/Edición & Anuncios Valencia & $\begin{array}{l}\text { Anuncios Madrid } \\
\text { relacionados }\end{array}$ & Ejemplares \\
\hline $\begin{array}{l}\text { La batalla de Baylen, } \\
\text { Reding y Dupont }\end{array}$ & \multirow[b]{3}{*}{$\begin{array}{l}\text { Londres, P.Weldon, } \\
\text { Goulding, Phipps, } \\
\text { D'Almaine, } 1809^{56}\end{array}$} & \multirow{4}{*}{$\begin{array}{l}G V^{57}, 29-11-1808 \\
D V^{58}, 4-12-1808 \\
G V, 6-12-1808 \\
D V, 20-2-1809\end{array}$} & \multirow{2}{*}{$\begin{array}{l}G M^{59}, 4-11-1808, \\
11-11-1808^{60} \\
\text { (Madrid, Dávila) }\end{array}$} & $\begin{array}{l}\text { E-Mn: Mp/2391/7 } \\
\text { GB-Lbl: h.125.(22.) }\end{array}$ \\
\hline $\begin{array}{l}\text { La sumisión de dicho á } \\
\text { nuestras tropas }\end{array}$ & & & & \\
\hline $\begin{array}{l}\text { Marcha figurada á la } \\
\text { entrada de nuestras } \\
\text { tropas al pueblo [Ma- } \\
\text { drid] }\end{array}$ & & & $\begin{array}{l}\text { GM, 30-9-1808 } \\
\text { (Madrid, almacén } \\
\text { carrera S. Jerónimo) } \\
\text { GM, 4-11-1808, } \\
\text { 11-11-1808 } \\
\text { (Madrid, Dávila) }\end{array}$ & \\
\hline $\begin{array}{l}\text { Rondó con variaciones á } \\
\text { la Proclamación de } \\
\text { nuestro amado Fernan- } \\
\text { do VII }\end{array}$ & & & $\begin{array}{l}D M, 10-9-1808 \\
\text { GM, 4-11-1808 } \\
\text { (Madrid, Escribano y } \\
\text { Pérez) }\end{array}$ & \\
\hline $\begin{array}{l}\text { Canción que se canta en } \\
\text { la Comedia los Patrio- } \\
\text { tas de Aragón }\end{array}$ & $\begin{array}{l}\text { Impresa en Cádiz, } \\
\text { Nicolás Gómez de } \\
\text { Requena, ¿1808? }\end{array}$ & $\begin{array}{l}G V, 29-11-1808 \\
D V, 4-12-1808 \\
G V, 6-12-1808\end{array}$ & $\begin{array}{l}D M^{61}, 4-11-1808 \\
\text { (Madrid, Dávila) } \\
\text { GM,11-11-1808 } \\
\text { (Madrid, almacén } \\
\text { carrera S. Jerónimo) }\end{array}$ & E-Mn; R/60280(37) \\
\hline Las Glorias de Aragón & & $\begin{array}{l}G V, 6-12-1808 \\
D V, 20-2-1809\end{array}$ & \multirow{2}{*}{$\begin{array}{l}\text { GM, 11-11-1808 } \\
\text { (Madrid, almacén } \\
\text { carrera S. Jerónimo) }\end{array}$} & \\
\hline $\begin{array}{l}\text { Décima glosada á } \\
\text { Napoleón }\end{array}$ & & $G V, 6-12-1808$ & & \\
\hline $\begin{array}{l}\text { Canción: Dupont } \\
\text { rendido }\end{array}$ & [¿Manuel Quijano?] & $\begin{array}{l}G V, 6-12-1808 \\
D V, 20-2-1809\end{array}$ & \multirow{2}{*}{$\begin{array}{l}\text { DM, 7-9-1808 } \\
\text { GM, 30-9-1808 } \\
\text { (Madrid, almacén } \\
\text { carrera S. Jerónimo) }\end{array}$} & E-Mn: MP/1138(2) \\
\hline La libertad de España & & GV, 6-12-1808 & & \\
\hline $\begin{array}{l}\text { Los Patriotas de Sevilla } \\
\text { á su General Reding }\end{array}$ & & $D V, 20-2-1809$ & & \\
\hline $\begin{array}{l}\text { Marcha dedicada a } \\
\text { nuestras tropas/exércitos }\end{array}$ & $\begin{array}{l}\text { D.F.S. } \\
\text { [¿Don Fernando } \\
\text { Sor?] }\end{array}$ & $\begin{array}{l}G V, 6-12-1808 \\
D V, 20-2-1809\end{array}$ & $\begin{array}{l}D M, 4-10-1808 \\
\text { (Madrid, Cerro y } \\
\text { Bengoechea) }\end{array}$ & E-Mn, R/60280(37) \\
\hline $\begin{array}{l}\text { Canción y seguidilla } \\
\text { que se cantó en Burgos } \\
\text { en la Proclamación de } \\
\text { nuestro Monarca }\end{array}$ & [José León] & DV , 20-2-1809 & $\begin{array}{l}D M, 16-8-1808 \\
\text { (Madrid, almacén } \\
\text { carrera S. Jerónimo) }\end{array}$ & $\begin{array}{l}\text { Miami U., Richter } \\
\text { Library, Lady Clive } \\
\text { Collection, ASM } 0240^{62}\end{array}$ \\
\hline
\end{tabular}

${ }^{56}$ Registrada en el London Stationers' Hall de Londres el 31-8-1809. Michael Kassler: Music Entries at Stationers' Hall: 1710-1818, Ashgate, 2013, p. 636.

${ }^{57}$ Gazeta de Valencia.

${ }^{58}$ Diario de Valencia.

${ }^{59}$ Gazeta de Madrid.

${ }^{60}$ Véase B. Jeffery: España de la guerra..., pp. 316-317.

${ }^{61}$ Diario de Madrid.

${ }^{62}$ Celsa Alonso: La canción lírica española en el s. XIX, Madrid, ICCMU, 1998, p. 44. 
Como constata el cuadro 1, el primer lote de piezas publicitado en los primeros dos anuncios del establecimiento valenciano ${ }^{63}$ posee un significativo paralelismo con otro anunciado por la librería madrileña de Dávila en noviembre de $1808^{64}$. A partir del tercer anuncio ${ }^{65}$, y sobre todo en el cuarto y último ${ }^{66}$, las obras anunciadas se corresponden con piezas publicitadas por otras librerías madrileñas que colaboraban entre sí, como las de Escribano y de Esparza ${ }^{67}$. Entre ellas destaca la correspondencia de obras con las publicitadas por el almacén de música y papel rayado de la carrera de San Jerónimo de Mateo Mintegui ${ }^{68}$. Estas correlaciones de obras, con un lapso de tan solo 25 días entre algunos anuncios de Madrid y deValencia, parecen confirmar una corriente difusora de música patriótica desde la capital, al contrario de lo que ocurría con otros centros productores ya ocupados por las tropas francesas ${ }^{69}$.

En octubre de 1809, en los puestos móviles de distribución del Diario de Valencia $^{70}$, se comenzaron a ofrecer también algunas canciones patrióticas (tabla 2), acompañando a otras comedias sin musicar. Estos puestos ya no volvieron a publicitar obras de música en prensa hasta después de la guerra.

${ }^{63}$ Gazeta de Valencia, n. ${ }^{\circ}$ 55, 29-11-1808, p. 628; Diario de Valencia, n. ${ }^{\circ}$ 64, 4-12-1808, p. 260.

${ }^{64}$ Dávila compartía el trabajo de un copista anónimo (DC) con la librería de Campo y ofrecía ediciones manuscritas sencillas. L. Bertran, A. Lombardía, J. Ortega: "La colección de manuscritos...", pp. 150-151, 153, 159.

${ }^{65}$ Gazeta de Valencia, n. ${ }^{\circ}$ 57, 6-12-1808, p. 652.

${ }^{66}$ Diario de Valencia, n. ${ }^{\circ}$ 51, 20-2-1809, p. 204.

${ }^{67}$ Gazeta de Madrid, n. ${ }^{\circ} 128,28-9-1808$, p. 1216; n. ${ }^{\circ} 141,4-11-1808$, p. 1438, respectivamente. Ambas librerías, no especializadas en música, compartieron los mismos títulos de obras en los anuncios. Además, la de Esparza tenía como copista a Antonio Pérez, al igual que la librería de Arribas L. Bertran, A. Lombardía, J. Ortega: "La colección de manuscritos...", pp. 151, 159.

${ }^{68}$ Fundado en 1805, tenía al menos tres copistas a sueldo, ofreciendo distintos niveles de acabado y precio de las obras, además de música técnicamente superior y para grandes plantillas. L. Bertran, A. Lombardía, J. Ortega: "La colección de manuscritos...", pp. 156-160.

${ }^{69}$ Barcelona lo estuvo desde el 20 de febrero de 1808 hasta el 24 de mayo de 1814. O. Brugarolas Bonet: "El comercio de partituras...", pp. 169-170.

${ }^{70}$ Diario de Valencia, n. ${ }^{\circ} 22,22-10-1809$, p. 88. La sede del periódico ejercía habitualmente de intermediaria entre particulares en la compraventa de partituras e instrumentos, tanto más en épocas de cierre de negocios específicos, de la misma forma que ocurría en Barcelona. O. Brugarolas Bonet: "El comercio de partituras...", p. 169. 
Cuadro 2. Música patriótica en los puestos del Diario de Valencia (1809)

\begin{tabular}{|c|c|c|c|}
\hline Títulos partituras & Autor/Editor/Copista & Anuncio Valencia & Ejemplares \\
\hline $\begin{array}{l}\text { Himno marcial, con un soneto } \\
\text { al Señor D. Fernando Séptimo }\end{array}$ & $\begin{array}{l}\text { Málaga, Ed. Carreras e } \\
\text { hijos [texto] }\end{array}$ & \multirow{4}{*}{$D V, 22-10-1809$} & $\begin{array}{l}\text { E-Mn: col. Gómez Imaz, } \\
\text { R/61980; R/61981 }\end{array}$ \\
\hline \multicolumn{2}{|c|}{$\begin{array}{l}\text { Canciones en elogio del archi- } \\
\text { duque Carlos. }\end{array}$} & & \\
\hline \multicolumn{2}{|l|}{ Canción Patriótica } & & \\
\hline Canción de un Artillero & $\begin{array}{l}\text { [¿Artillero del Castillo?] } \\
\text { compuesta en Manresa por } \\
\text { "José Puich" }\end{array}$ & & $\begin{array}{l}\text { E-Mn: col. Gómez Imaz, } \\
\text { R/ } 62510\end{array}$ \\
\hline
\end{tabular}

También a finales de 1809, la recientemente abierta librería de Cabrerizo, situada en la plaza del colegio del Corpus Christi en Valencia, publicaba dos anuncios de música patriótica (cuadro 3). De ellos es interesante señalar que tanto una obra del primer anuncio como las tres primeras del segundo (cuadro 3) ya habían sido anunciadas desde el almacén de la calle Gracia el 20 de febrero de 1809. Esto podría confirmar la identificación propuesta de Mariano Cabrerizo con el agente anónimo que anunciaba obras desde dicho almacén, así como la compra del stock o un distribuidor compartido. Además de esto, se observa la llegada a Valencia de los grandes títulos musicales del género, producidos y anunciados en Sevilla y Cádiz, sedes de la Junta Suprema Central una vez ocupada la capital del reino ${ }^{71}$.

${ }^{71}$ V. Sánchez López: “La música en Andalucía...", p. 299. 


\section{Cuadro 3. Música patriótica en la librería de Cabrerizo (1809)}

\begin{tabular}{|c|c|c|c|c|}
\hline Títulos partituras & Autor/Editor & Anuncio Valencia & Otros anuncios & Ejemplares \\
\hline \multicolumn{5}{|l|}{ Las Quexas de España } \\
\hline \multicolumn{5}{|l|}{ La perfidia del tirano } \\
\hline $\begin{array}{l}\text { El soldado español en el } \\
\text { campo de batalla }\end{array}$ & $\begin{array}{l}\text { Sevilla, F. Layglesia y } \\
\text { Darrac, } 1809 \text { (texto) } \\
\text { Tres versiones de } \\
\text { música: } \\
\text { - J.C. Asensio, 6/8 } \\
\text { (Hidalgo, Sevilla) } \\
\text { - Anónimo, 4/4 } \\
\text { - FJ. de Molle, 6/8 } \\
\text { (Quintana, Cádiz) }\end{array}$ & \multirow{6}{*}{ DV,25-11-1809 } & $\begin{array}{l}D M C^{73}, 14-10-1809 \\
19-11-1809 \\
E C^{74}, 10-10-1810 \\
D M, 22-6-1813\end{array}$ & Varias localizaciones ${ }^{75}$ \\
\hline Los patriotas de Sevilla ${ }^{76}$ & & & & \\
\hline $\begin{array}{l}\text { La Canción del General } \\
\text { Cuesta }^{77}\end{array}$ & \multirow{4}{*}{$\begin{array}{l}\text { [J.B. Arriaza y música } \\
\text { de F. Sor] } \\
\text { Varias ediciones y } \\
\text { copias manuscritas: } \\
\text { - Cádiz, Gómez de } \\
\text { Requena, } 1809 \\
\text { - Londres, Bensley, } 1810\end{array}$} & & $G S^{78}, 24-4-1809$ & $\begin{array}{l}\text { E-Mn: varias localiza- } \\
\text { ciones }^{79} \text {, } \\
\text { MP/3183/5 (Valencia, } \\
1810 \text { ) }\end{array}$ \\
\hline $\begin{array}{l}\text { Los Vencedores de la } \\
\text { Patria }^{80}\end{array}$ & & & DMC: $22-8-1808$ & $\begin{array}{l}\text { E-Mn: varias localiza- } \\
\text { ciones }^{81}\end{array}$ \\
\hline $\begin{array}{l}\text { Marcha de Marte a los } \\
\text { soldados españoles }\end{array}$ & & & & $\begin{array}{l}{[\mathrm{E}-\mathrm{Mn}:} \\
\mathrm{MC} / 5307 / 4]^{83}\end{array}$ \\
\hline $\begin{array}{l}\text { Marcha sensible } \\
\text { a nuestro soberano } \\
\text { Fernando Séptimo }\end{array}$ & & & & \\
\hline $\begin{array}{l}\text { Canción y seguidilla } \\
\text { dedicada a nuestro } \\
\text { Soberano }^{84}\end{array}$ & [José León] & \multirow{3}{*}{$D V, 27-11-1809$} & $\begin{array}{l}D M, 16-8-1808 . \\
\text { GM, 30-8-1808, } \\
\text { (Madrid, almacén } \\
\text { carrera S. Jerónimo) }\end{array}$ & $\begin{array}{l}\text { Miami University, } \\
\text { Richter Library: Lady } \\
\text { Clive Harriet Collec- } \\
\text { tion, ASM } 0240\end{array}$ \\
\hline $\begin{array}{l}\text { Rondó con variaciones e } \\
\text { intento a la Proclamación }\end{array}$ & Fernández & & $\begin{array}{l}\text { GM, 8-11-1808, } \\
\text { (Madrid, Campo) }\end{array}$ & \\
\hline $\begin{array}{l}\text { La famosa batalla de } \\
\text { Baylen }\end{array}$ & $\begin{array}{l}\text { Londres, P.Weldon, } \\
\text { Goulding, Phipps, } \\
\text { D'Almaine, } 1809\end{array}$ & & $\begin{array}{l}\text { GM, 4-11-1808, } \\
\text { 11-11-1808 } \\
\text { (Madrid, Dávila) }\end{array}$ & $\begin{array}{l}\text { E-Mn: Mp/2391/7 } \\
\text { GB-Lbl: Music } \\
\text { Collections h.125. (22.) }\end{array}$ \\
\hline
\end{tabular}

${ }^{72}$ Véase B. Jeffery: España de la guerra..., pp. 188-191, 233.

${ }^{73}$ Diario Mercantil de Cádiz.

${ }^{74}$ El Conciso, Cádiz.

${ }^{75}$ E-Mm: Depósito V 10100073447 10.425; E-Mn: MS MP/1989; GB-Lam: Clive MS 309, pp. 239245; E-Mn: M/2233.

${ }^{76}$ Ya aparecido en los anuncios del almacén de la calle de Gracia n. ${ }^{\circ} 24$ (Los Patriotas de Sevilla a su General Reding).

${ }^{77}$ [iLos defensores de la Patria?].

${ }^{78}$ Gazeta de Sevilla.

79 E-Mn: M/188(2); R/60280(37); MP/3180/14; R/62031; R/62032; MP/1989(15); R/62539, entre otros.

${ }^{80}$ [Himno de la Victoria].

${ }^{81}$ E-Mn: M/2233; R/60280(17); VC/2880/18; Mss/12741(48), entre otros.

82 [Vivan de las españas los soldados de marte].

${ }_{83}$ Canción Patriótica manuscrita en La mayor (3/8): "Vivan de las Españas los soldados de Marte". (http://bdh.bne.es/bnesearch/detalle/bdh0000085835, consulta 23-12-2019).

${ }^{84}$ [Canción con seguidilla con la que solemnizó la ciudad de Burgos á su invicto Rei D. Fernando VII]. 
Desde junio de 1810 hasta enero de 1811 se produjo un significativo aumento de los anuncios de partituras patrióticas, probablemente motivado por el fracaso del segundo asedio francés, acontecido en marzo ${ }^{85}$.

Cuadro 4. Música patriótica en Valencia, diversas librerías (1810-1811)

\begin{tabular}{|c|c|c|c|c|c|}
\hline Librerías & Títulos & Autor/Editor & Anuncios & & Ejemplares \\
\hline \multirow[t]{2}{*}{ Mallén } & $\begin{array}{l}\text { Canción de guerra dedicada } \\
\text { al excmo. Señor Marqués de } \\
\text { la Romana }\end{array}$ & \multirow{2}{*}{$\begin{array}{l}\text { [¿Josef Acuña?] } \\
\text { copia de Josef } \\
\text { Acuña }\end{array}$} & \multirow[t]{2}{*}{$\begin{array}{l}\text { DV }, 12-6-1810 \\
D V, 19-12-1810\end{array}$} & & \\
\hline & El Laurel de Valencia & & & & \\
\hline \multirow{3}{*}{ Cabrerizo } & $\begin{array}{l}\text { La defensa de Valencia y } \\
\text { castigo de traidores }\end{array}$ & $\begin{array}{l}\text { Félix Enciso } \\
\text { Castrillón [texto] }\end{array}$ & \multirow[b]{2}{*}{ DV, 16-6-1810 } & $\begin{array}{l}D M, 14-11- \\
1808, \text { (Madrid, } \\
\text { almacén calle del } \\
\text { Príncipe) }\end{array}$ & \\
\hline & $\begin{array}{l}\text { Elogio de Fernando Sépti- } \\
\text { mo, detenido y preso en el } \\
\text { palacio de Valencey en } \\
\text { Francia por el Emperador } \\
\text { Napoleón }\end{array}$ & $\begin{array}{l}\text { Melchor Anda- } \\
\text { rió y Castellvell } \\
\text { [texto] }\end{array}$ & & & \\
\hline & $\begin{array}{l}\text { Himno a Badajoz Vencedora } \\
\text { el } 11 \text { de febrero de } 1810\end{array}$ & $\begin{array}{l}\text { F. J. de Molle. } \\
\text { Cádiz, Imprenta } \\
\text { de Quintana }\end{array}$ & DV, 16-10-1810 & EC, 2-10-1810 & $\begin{array}{l}\text { E-Ms: } \\
\text { MS FH/41288 } \\
\text { E-Mn: } \\
\text { MP/1138(1) }\end{array}$ \\
\hline \multirow[b]{2}{*}{ Jaime Faulí } & $\begin{array}{l}\text { Himno/Marcha a los patrio- } \\
\text { tas extremeños }\end{array}$ & & \multirow{2}{*}{$\begin{array}{l}D V, 16-6-1810 \\
29-10-1810 \\
7-1-1811\end{array}$} & & \\
\hline & $\begin{array}{l}\text { Canción fúnebre del } 2 \text { de } \\
\text { mayo }^{86}\end{array}$ & $\begin{array}{l}\text { J. B. de Arriaza y } \\
\text { Benito Pérez } \\
\text { (música) }\end{array}$ & & $D M C, 3-5-1810$ & $\begin{array}{l}\text { Varias localiza- } \\
\text { ciones }^{87}\end{array}$ \\
\hline Minguet & Al Arma corred Españoles & $\begin{array}{l}\text { Cádiz, Imprenta } \\
\text { de Quintana }\end{array}$ & $1-11-1810$ & & $\begin{array}{l}\text { Varias localiza- } \\
\text { ciones }^{88}\end{array}$ \\
\hline \begin{tabular}{|l|} 
Francisco \\
Ximeno \\
[particular] \\
\end{tabular} & Los defensores de la Patria & $\begin{array}{l}\text { Arriaza-Sor } \\
\text { transcripción F. } \\
\text { Ximeno }\end{array}$ & \multicolumn{2}{|c|}{ [transmisión privada] } & $\begin{array}{l}\text { E-Mn: } \\
\text { MP/ 3183/5 }\end{array}$ \\
\hline \begin{tabular}{|l|} 
Salvador \\
Faulí
\end{tabular} & $\begin{array}{l}\text { Fuego y sangre: marcha } \\
\text { española }\end{array}$ & Josef Acuña & $D V, 7-1-1811$ & $\begin{array}{l}\text { DM, 19-9-1808, } \\
\text { (Madrid, Esparza) }\end{array}$ & E-Mn: R/62157 \\
\hline
\end{tabular}

De los diecisiete anuncios que publicaron seis establecimientos, ocho contenían canciones patrióticas. La librería de Mallén ${ }^{89}$ había comenzado a ofrecer música patriótica entre varias piezas de temática lírica y alguna de música po-

${ }^{85}$ El mariscal francés Louis Gabriel Suchet llegó a Valencia el 5 de marzo. En esta ocasión, el entonces capitán general, José Caro, fue capaz de prever la situación y reforzó las fortificaciones, estableciendo un férreo control sobre liberales y afrancesados dentro de la ciudad, de los que Suchet esperaba una insurrección. Tras cinco días atrincherados en el recientemente demolido Palacio del Real, los franceses se retiraron hacia Aragón. M. Sanchis: La ciudad de Valencia..., pp. 274-275.

${ }^{86}$ Probablemente se corresponda con Recuerdos del 2 de mayo: canción elegíaca. Véase B. Jeffery: España de la guerra..., pp. 225-227, 362-364 y M. Gembero-Ustárroz: "Reflejos de la música...", p. 151.

${ }^{87}$ Véase B. Jeffery: España de la guerra..., pp. 262-265.

${ }^{88}$ E-Mn: R/62547; MP/1138(2); E-Ms: FH/41286; E-Mp: col. Sáiz VIII/18308.

${ }^{89}$ Diario de Valencia, n. ${ }^{\circ} 73$, 12-6-1810, p. 292. 
pular. El autor del acompañamiento para pianoforte y guitarra de las dos canciones anunciadas por Mallén, según refiere el segundo anuncio del establecimiento ${ }^{90}$, era el cantante y pianista valenciano Josef Francisco Acuña y Castells (nacido en Xàtiva en 1778), tenor de la iglesia colegial de San Felipe (Xàtiva) ${ }^{91}$ que, junto con Manuel García ${ }^{22}$, había destacado como una de las mejores voces del momento en los teatros de Madrid de principio de siglo ${ }^{93}$. Acuña había protagonizado ese mismo año dos conciertos públicos de piano y música vocal en Valencia con éxito y, posiblemente por ello, el librero Pedro Juan Mallén contrató sus servicios para copiar y realizar arreglos musicales, además de componer varias canciones y piezas líricas para pianoforte ${ }^{94}$. A partir de 1811, esta librería dejó de publicitar la venta de material musical hasta el final de la guerra.

Por otra parte, Mariano Cabrerizo publicitaba dos comedias literarias en junio de 1810 en el apartado de música ${ }^{95}$ y, en octubre, un himno atribuido a

${ }^{90}$ Viardot hablaba gráficamente de multiautoría en la composición de la primera pieza al afirmar: "uno empieza, otro continua y un tercero concluye. Así es, por ejemplo, como se ha compuesto la bella canción patriótica del Marqués de la Romana". Luis Viardot: Estudios sobre la historia de las instituciones, literatura, teatro y bellas artes en España, Logroño, Ruiz, 1841, p. 270.

${ }^{91}$ Este personaje, sobrino de los célebres músicos setabenses Juan y Joaquín Acuña es objeto actualmente de un estudio in fieri llevado a cabo por el autor.

${ }^{92}$ Manuel García (1775-1832) fue un cantante, compositor, productor de ópera, director de escena español y uno de los personajes más influyentes de la ópera del siglo XIX. Constituyó la dinastía más importante de cantantes y profesores de canto del siglo XIX: los hijos que tuvo de su unión con Joaquina Briones fueron María Malibrán (1808-1836), Pauline Viardot-García (1821-1910) y Manuel Patricio Rodríguez García (1805-1906). Alberto Romero Ferrer, Andrés Moreno Mengíbar: Manuel García: de la tonadilla escénica a la ópera española (1775-1832), Cádiz, Servicio Publicaciones de la Universidad de Cádiz, 2006, pp. 180, 194, 197.

${ }^{93}$ Baltasar Saldoni: Diccionario biográfico-bibliográfico de efemérides de músicos españoles, tomo IV, Madrid, Pérez-Dubrull, 1881, p. 8. (reed. facs. Valencia, Librerías París-Valencia, 2003).

94 “[...] se advierte que todas las canciones [.. . ] con acompañamiento de guitarra se pondrán para piano, y las de éste para guitarra, mediante encargo particular". Diario de Valencia, n. ${ }^{\circ}$ 73, 12-6-1810, p. 292.

${ }^{95}$ Diario de Valencia, n. ${ }^{\circ} 77$, 16-6-1810, p. 307. Estas comedias se insertaron en el anuncio bajo el epígrafe "MÚSICA". El texto de la primera era obra de Félix Enciso Castrillón (ca. 1780-ca. 1840), literato que fue profesor en el Seminario de Nobles de Vergara, en el Conservatorio de Madrid y en la Universidad Literaria. Se representó en el teatro de la Cruz (Madrid, 29-10-1808) y fue reimpresa en Cádiz (1808) y en Valencia, aquí con el título invertido: El escarmiento de traidores y defensa de Valencia, 1809. En diciembre de 1808 se anunciaba como comedia en cuatro actos en la valenciana librería de Navarro. Gazeta de Valencia, n. ${ }^{\circ}$ 57, 6-12-1808, p. 652. El texto de la segunda corresponde al clérigo Melchor Andarió y Castellvell, uno de los redactores del Diario de Sevilla en 1809 , editado en Madrid por la imprenta de Eusebio Álvarez (1808) y en Valencia por Benito Monfort en el mismo año, tal y como se comprueba en el ejemplar conservado por la biblioteca de la Universitat Pompeu Fabra de Barcelona (http://mdc.csuc.cat/cdm/ref/collection/guerraInd/id/194, consulta 2412-2019) y por otro ejemplar en E-Mn: R/60379(7) (http://bdh.bne.es/bnesearch/detalle/ bdh0000140192, consulta 3-1-2020). Años más tarde, La Defensa de Valencia volvió a representarse como comedia en tres actos en el Teatro de la Cruz en Madrid, durante el verano de 1813 (Diario de Madrid, n. ${ }^{\circ}$ 203-207, 22 al 26-7-1813, pp. 100-116). Véase Ivy L. McClelland, Ann L. Mackenzie: "A Propaganda Play of 1808: F. Enciso Castrillón's La defensa de Valencia y castigo de traidores", Bulletin of Hispanic Studies, 86, 2009, pp. 238-257. 
Francisco José de Molle ${ }^{96}$. La librería de Jaime Faulí Albors, hermano del también librero Salvador ${ }^{97}$, comenzó a vender piezas de canto y pianoforte o guitarra a mediados de junio de ese año, además de otras para flauta y violín. Desde octubre y al menos hasta enero de 1811 incorporó otras dos canciones para guitarra a sus existencias, pero parece que no consiguió ningún copista para adaptarlas a piano ${ }^{98}$. En octubre de ese año, la librería de Minguet publicó anuncios de música patriótica compuesta por un músico anónimo de la capital. El texto del primer anuncio hablaba de la puesta en música de una Nueva canción patriótica, a dúo o a solo, por un "profesor natural de esta ciudad, que desea el mayor adelantamiento en esta arte, y la aprobación de los inteligentes y aficionados" "99; posteriormente la tituló Canción nueva patriótica: Al arma, españo$l e s^{100}$. Con el mismo título existía ya una tirana que fue escrita antes de la batalla de Bailén en 1808; el texto había sido impreso sin música en Madrid, Écija y Cádiz ${ }^{101}$.Además, se conserva el registro con la misma letra de una Canción de llamada para fortepiano en compás de 3 por 8 en el catálogo de Adolfo de Castro ${ }^{102}$, así como dos piezas en 3/8 para voz y piano con músicas completamente divergentes: la primera es una Canción patriótica en La mayor proveniente de la colección Gómez-Imaz de la Biblioteca Nacional ${ }^{103}$ y la segunda una Tirana patriótica en Sol mayor conservada en la Biblioteca del Senado ${ }^{104}$. La falta de datos del anuncio de Minguet acerca del profesor natural de la ciudad que musicó el texto enValencia y de las características de la obra imposibilita por el momento asociar el ejemplar valenciano con uno de estos dos conservados.

El año de 1811 estuvo lleno de privaciones para la ciudad de Valencia. Aunque las librerías de Salvador Faulí de la plaza del Colegio del Corpus Christi y la de su hermano Jaime en la calle del Mar (frente al convento

${ }^{96}$ Diario de Valencia, n. ${ }^{\circ} 16,16-10-1810$, p. 64 . Este himno se compuso para conmemorar la resistencia de la ciudad en el llamado "primer sitio de Badajoz" (enero a marzo de 1810). Consta de 4 hojas, se imprimió en Cádiz por Quintana y se vendía en Casa de Font y Closas. Se conserva un ejemplar en E-Mn: MP/1138(1).

${ }^{97}$ Ambos eran hijos del también librero Salvador Faulí Martí, activo en la segunda mitad del s. XVIII. Véase José Enrique Serrano Morales: Reseña histórica en forma de diccionario de las imprentas que han existido en Valencia desde la introducción del arte tipográfico en España hasta el año 1868, tomo 2, Valencia, imprenta de F. Doménech, 1898-1899, pp. 144-148.

${ }^{98}$ Diario de Valencia, n. ${ }^{\circ} 77,16-6-1810$, p. 307; n. ${ }^{\circ} 29,29-10-1810$, p. 116; n. ${ }^{\circ}$ 7, 7-1-1811, p. 28.

${ }^{99}$ Ibid., n. ${ }^{\circ} 77,16-10-1810$, p. 307.

${ }^{100} \mathrm{Ibid}$. n. ${ }^{\circ}$ 52, 1-11-1810, p. 128. No debe confundirse con la canción A las armas corred, españoles, con música de Mateo Corral y mucho más difundida. B. Lolo: "La música al servicio...", p. 229.

${ }^{101}$ B. Jeffery: España de la guerra..., pp. 39, 74-75, 313; M. Gembero-Ustárroz: "El ambiente musical...", p. 104.

102 E-Mn: Mss/12853(66).

${ }^{103}$ E-Mn: R/62547 (http://bdh.bne.es/bnesearch/detalle/bdh0000085835, consulta 26-12-2019). El texto Al arma corred, españoles es un largo romance similar escrito por Juan Meléndez Valdés que fue impreso en Valencia por Joseph Estevan y hermanos.

${ }^{104}$ E-Ms: FH 41286. 
de Santa Tecla) ofrecieron algunas canciones entre finales de diciembre de 1810 y enero de $1811^{105}$, los anuncios de literatura musical habían desaparecido prácticamente de la prensa local. Jaime Faulí seguía ofreciendo únicamente piezas con acompañamiento de guitarra, lo que parece revelar la dificultad de encontrar copistas autóctonos con conocimientos de tecla dispuestos a desarrollar dicha labor. Pese a ello, Salvador Faulí contrató a un "aficionado" que arreglaba el acompañamiento de las canciones a guitarra o pianoforte a demanda ${ }^{106}$. La única obra nueva de entre las anunciadas entonces por Salvador Faulí era Fuego y sangre, marcha española con acompañamiento de guitarra, de la que no se ofrecía nombre de autor. Sin embargo, en este caso sí que resulta posible adscribir la obra a un personaje concreto. Dado que existe en E-Mn un manuscrito compuesto por José Francisco Acuña ${ }^{107}$ cuyo íncipit literario comienza con "Fuego y sangre, españoles" - una versión alternativa para coro de hombres y piano- es muy probable que la citada pieza fuera compuesta por Acuña y que él mismo fuera el "aficionado" que arreglaba los acompañamientos. Brian Jeffery refrenda la hipótesis sobre la autoría de la obra ${ }^{108}$, afirmando que fue compuesta probablemente ca. 1808 debido a dos cuestiones: en primer lugar, la referencia al ejército valenciano en el título del único ejemplar conservado ("que se canta en el exército nacional del Reyno de Valencia") parece relacionarlo con la temida entrada de tropas valencianas "con guitarrillas, cantando, y a la par amenazando" en Madrid el 13 de agosto de $1808^{109}$; en segundo lugar, su datación en 1808 es plausible ya que existía una obra del mismo autor y título similar que se anunciaba ya en el Diario de Madrid en 1808 en los siguientes términos: "Marcha española á dúo para piano, alusiva por todas sus partes á las cosas del día, por el Sr. Josef Acuña: su precio 10 rs.Véndese en casa de Esparza, frente a la Puerta del Sol, frente alVivac" ${ }^{\prime 110 .}$

${ }^{105}$ Fuego y Sangre, marcha española con acompañamiento de guitarra en la de Salvador Faulí y las ya anunciadas Canción Fúnebre del 2 de Mayo y la Marcha a los Patriotas extremeños en la de Jaime Faulí. Diario de Valencia, n. ${ }^{\circ}$ 7, 7-1-1811, p. 28.

106 Ibid.

${ }^{107}$ E-Mn: Marcha patriótica que se canta en el exército nacional del Reyno de Valencia puesta en música y con acompañamiento de piano-forte por $D^{n}$. Josef Franco. Acuña ("Fuego y sangre, españoles").

108 B. Jeffery: España de la guerra..., pp. 107-109.

109 Antonio Alcalá Galiano: Recuerdos de un anciano. Obras escogidas, tomo I, Biblioteca de autores españoles, Atlas, 1955, p. 44, citado en B. Jeffery: España de la guerra..., p. 83.

${ }^{110}$ Diario de Madrid, n. ${ }^{\circ} 43,19-9-1808$, p. 244. La librería de Esparza, en la Puerta del Sol, vendía libros, grabados, estampas y música, muchas veces asociada con la de Escribano (calle de las Carretas) y ocasionalmente con las de Campo y Dávila. Todas ellas ofrecían "ediciones manuscritas sencillas, sin portadas grabadas, con un repertorio breve, fácil y popular". L. Bertran, A. Lombardía, J. Ortega: "La colección de manuscritos...”, pp. 153, 159. 


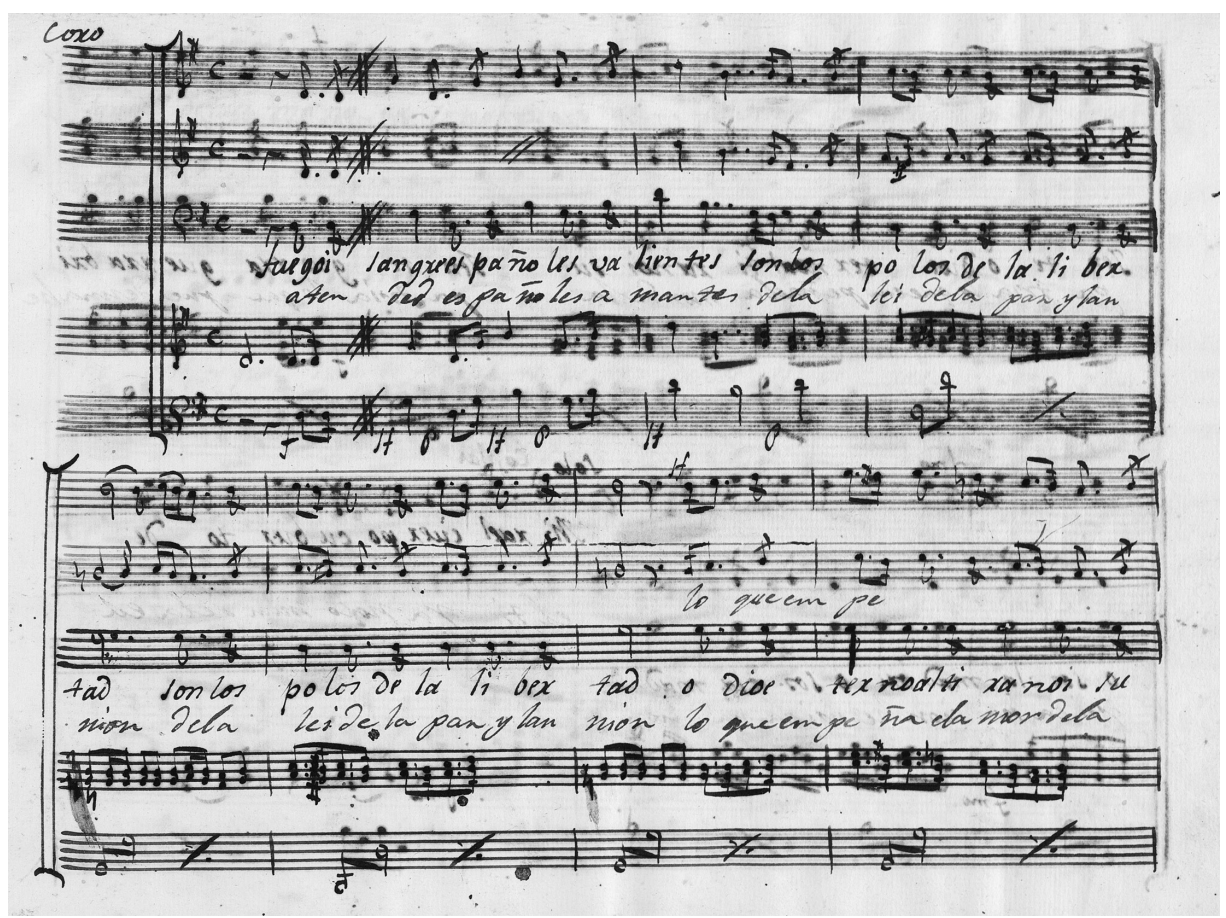

Ilustración 3. Fragmento de la Marcha Patriótica que se canta en el exército real de Valencia de Josef Acuña, "Fuego y sangre, españoles" (BNE)

En el paréntesis producido por la ocupación francesa de la ciudad (enero de 1812-julio de 1813), no se publicitó música política: Acuña se embarcó hacia Mallorca, siendo acogido por el editor e impresor liberal valenciano Miguel Domingo $^{111}$. La librería de Bruno, en la plaza de Calatrava, fue la única que anunció ese año canciones líricas, únicamente con acompañamiento de guita$\mathrm{rra}^{112}$. Finalmente, el 6 de julio de 1813, entraron las tropas del general Villacampa en una ciudad apática y contenida que celebró con una procesión la publicación de la Constitución Española ${ }^{113}$. La librería de Manuel López -inactiva en la venta de esta literatura musical desde 1808- fue la que publicitó en abril de 1814 el último lote de canciones a través de dos anuncios, de los cuales únicamente uno de ellos correspondía a partituras patrióticas de reciente

${ }^{111}$ José Joaquín Esteve Vaquer: Som pobres de solemnitat! Cap a l'emancipació del músic preromàntic a Palma de Mallorca, tesis doctoral, Universitat Autònoma de Barcelona, vol. IV, pp. 70-74.

112 Diario de Valencia, 7-10-1812 [sin número de página].

${ }^{113}$ Ibid., n. ${ }^{\circ} 8,20-7-1813$, pp. 31-32. 
composición y representación (cuadro 5). A ellos se les unieron otros de canciones en verso no musicadas tratando de motivar a algún autor profesional o músico aficionado a ponerles música ${ }^{114}$.

Cuadro 5. Canciones patrióticas en la librería de Manuel López $(1814)^{115}$

\begin{tabular}{|c|c|c|c|c|}
\hline Títulos & Autor/Editor & $\begin{array}{l}\text { Anuncio } \\
\text { Valencia }\end{array}$ & Anuncios foráneos & Ejemplares \\
\hline La España libre & & \multirow{5}{*}{$\begin{array}{l}D V, 6-4- \\
1814\end{array}$} & & $\begin{array}{l}\text { E-Mn: }[\mathrm{MSS} / 20092 / 7] \\
{[\mathrm{MC} / 5307 / 49]}\end{array}$ \\
\hline Batalla de Arapiles ${ }^{115}$ & $\begin{array}{l}\text { Letra: Francisco } \\
\text { Garnier } \\
\text { Música: Manuel Quijano } \\
\text { Madrid, imp. López } \\
\text { García (1813) }\end{array}$ & & & $\begin{array}{l}\text { E-Mn: } \\
\text { MC/5307/30 } \\
\text { R/62515 } \\
\text { MC/4837/71 } \\
\text { E-Ms: FH } 41289\end{array}$ \\
\hline $\begin{array}{l}\text { Himno al inmortal } \\
\text { Wellington }\end{array}$ & Sevilla, imp. Josef Hidalgo & & $\begin{array}{l}\text { El Redactor General, Cádiz } \\
\text { DM, 22-6-1813 }\end{array}$ & $\begin{array}{l}\text { E-Mn: MP/3172/16 } \\
\text {-Col. del Fraile vol. } \\
867 / 3.176\end{array}$ \\
\hline $\begin{array}{l}\text { El llanto de la } \\
\text { España }\end{array}$ & & & $\begin{array}{l}D M, \\
18-6-1813 \\
22-6-1813 \\
\text { 6-7-1813 (almacén carrera } \\
\text { S. Jerónimo) } \\
\end{array}$ & \\
\hline La derrota de Soult & $\begin{array}{l}\text { [Francisco de Paula } \\
\text { Martí] }\end{array}$ & & $\begin{array}{l}\text { GM, 19-8-1813, } \\
\text { (puesto de libros de Martín } \\
\text { Santos) }\end{array}$ & \\
\hline
\end{tabular}

Repertorio y tipologías: ejemplos de literatura musical revolucionaria, bélica, himnos laudatorios e himnos y canciones patrióticas en Valencia

En primer lugar, cabe decir que la música de contenido patriótico de la Guerra de la Independencia Española posee ciertas características estilísticas y funcionales propias de la música revolucionaria francesa ${ }^{116}$, así como de obras de temática bélica, especialmente relacionadas con las guerras napoleónicas. Por una parte, tanto las canciones que se utilizaron en torno la Revolución Francesa, como las conmemoraciones de batallas, marchas e himnos laudatorios, se convirtieron en vehículos de propaganda ideológica liberal que, en España, Floridablanca y la Inquisición no pudieron contener ${ }^{117}$. Por otra parte, también influyó la literatura musical de temática descriptivo-bélica que se basaba en la

${ }^{114}$ Como por ejemplo los Cantos Guerreros de Tirtéo, acomodados a la situación actual de España, puestos a la venta en Cabrerizo, Beneyto y López y en la plaza de la Constitución, los cuales estaban escritos "en metros fáciles de poner en música". Diario de Valencia, n. ${ }^{\circ}$ 63, 3-3-1814, p. 252.

115 Probablemente Velinton [Wellington] en Arapiles. Véase B. Jeffery: España de la guerra..., pp. 390-391.

${ }^{116}$ Véase M. Gembero-Ustárroz: "Reflejos de la música...”, pp. 143-147; M. Gembero-Ustárroz: "La música en España e Hispanoamérica...", pp. 178 y ss.

${ }^{117}$ J. M. Soto de Lanuza: "La música y el acontecimiento histórico"..., pp. 14 y ss. 
representación de eventos militares e históricos (batallas) por medio de piezas de música que trataban de reproducir el fragor de la contienda en sus distintas fases (marchas, toques de clarín, cañonazos, bombas) ${ }^{118}$. Esta tipología, aunque ya existía en etapas anteriores, adquirió un claro tono programático e ideológico en la música del periodo tratado ${ }^{119}$.

En Valencia poseemos varios ejemplos de la llegada y comercio de la literatura musical revolucionaria y bélica, como son las obras Minuete de la muerte de Robespierre y la Batalla de Marengo, episodio de la popular batalla napoleónica. Su venta se anunciaba ya en 1806 en la librería de Josef $\mathrm{Na}-$ varro $^{120}$. La segunda pieza, que incluía tres "alegros característicos" se correspondería con la obra compuesta entre 1803 y $1808^{121}$ por Bernard Viguerie (1761-1819), dotada al final de tres Airs que permiten relacionarla con la obra anunciada en Valencia ${ }^{122}$.

Desde los primeros meses de la contienda, la temática de estas obras se comenzó a vincular a los diversos acontecimientos bélicos peninsulares, adaptándose en su mayoría desde piezas dramáticas que se representaron en los teatros de las principales ciudades. En Valencia se anunciaron algunas de las obras más célebres, tales como la icónica y extensamente estudiada Batalla de Bailén $n^{123}$ anunciada en 1808 (cuadro 1) junto con la canción Dupont rendido, y, años más tarde, la Batalla de Arapiles, anunciada en 1814 junto con la Derrota de Soult (cuadro 5). Sobre la capitulación del general Dupont en Bailén (1808) existía ya un drama, La rendición de Dupont, ó el mejor triunfo de España, la victoria de Bailén, con música del compositor dramático Manuel Quijano (fallecido en

${ }^{118}$ Véanse por ejemplo las batallas documentadas en el Fondo Borbone de la Biblioteca Palatina de Parma (Batalla de Marengo, Batalla de Austerlitz, Batalla de Jena, Gran batalla del Rey de Prusia). L. Bertran, A. Lombardía, J. Ortega: "La colección de manuscritos...", pp. 151, 157, 171, 178, 180.

119 Laura Cuervo Calvo: El piano en Madrid (1800-1830): repertorio, técnica interpretativa e instrumentos, tesis doctoral, Universidad Complutense de Madrid, 2012, pp. 121, 130.

${ }^{120}$ Diario de Valencia, n. ${ }^{\circ} 63,5-12-1806$, p. 292.

${ }^{121}$ Bernard Viguerie: Bataille de Maringo, pièce militaire et historique pour le forte-piano avec accompagnement de violon et basse [...] par B. Viguerie. Euvre 8, París, autor, ca. 1800. Ejemplar en F-Pn sig. VM77118 (https://catalogue.bnf.fr/ark:/12148/cb39793316m, consulta 27-10-2020).

122 ler Air après la victoire, 2 me Air dans le genre egiptien, 3 me Air pas redoublé. De ella se conservan algunos ejemplares manuscritos en diversos fondos documentales, como son el Fondo Borbone de la Biblioteca Palatina de Parma y el Quaderno 2. ${ }^{\circ}$. Tomo $3^{\circ}$. Piezas para piano de la Biblioteca Nacional de España. L. Bertran, A. Lombardía, J. Ortega: "La colección de manuscritos...", pp. 151, 178; Laura Cuervo Calvo: El piano en Madrid..., pp. 123, 329, 386, 501 y 532.

${ }^{123}$ La Batalla de Bailén, del neoyorquino Peter Weldon, constituye una de las primeras y más estudiadas composiciones en la Guerra de la Independencia Española. Apareció impresa casi inmediatamente después de la victoria del ejército español en Bailén (22-6-1808). Véase Juan Pablo Pacheco Torres: "La batalla de Bailén en la música de la Guerra de la Independencia Española", Baylen 1808-2008: actas del Congreso Internacional "Baylen 1808-2008": Bailén, su impacto en la nueva Europa del siglo XIX y su proyección futura, Francisco Acosta Ramírez, Marta Ruiz Jiménez (coords.), 2009, pp. 593-620; B. Jeffery: España de la guerra..., pp. 136-156, 361-317. 
$1838)^{124}$. La canción homónima se anunció en Madrid en septiembre del mismo año ${ }^{125}$ y su partitura se conserva en una colección facticia manuscrita adquirida por la Biblioteca Nacional en $2015^{126}$. Por otro lado, la Batalla de Arapiles estaba basada en un drama en un acto reeditado enValencia por la imprenta de Estevan ${ }^{127}$ en 1813 y estrenado el verano del mismo año en el madrileño coliseo del Príncipe ${ }^{128}$. Brian Jeffery la identifica con la canción Wellington en Arapiles $^{129}$, de la cual se conserva un ejemplar en E-Mn ${ }^{130}$. Por último, la Derrota de Soult, vendida como canción para pianoforte en Madrid ${ }^{131}$, se basaba en una tonadilla que se insertaba, con escaso éxito ${ }^{132}$, en el seno de la comedia homónima representada en el Teatro de la Cruz en agosto de $1813^{133}$ atribuida al dramaturgo Francisco de Paula Martí1 ${ }^{134}$.

En segundo lugar, las marchas e himnos de contenido laudatorio hacían referencia a personalidades destacadas de la política y ejércitos victoriosos. En enero de 1808 , la citada librería de Josef Navarro anunciaba una edición manuscrita de la Arieta alusiva al magnifico Empleo de Grande Almirante de S. A. Smo. Príncipe de la Paz, dedicada a S. A. con acompañamiento de piano forte en dos versiones (en español e italiano) ${ }^{135}$. Por su parte, desde el diario se ofrecía en 1809 un Himno marcial, con un soneto al Señor D. Fernando Séptimo y unas Canciones en elogio del archiduque Carlos ${ }^{136}$. Asimismo, la introducción de himnos pro-ingleses como "símbolo del hermanamiento con la nación británica"137 se vio reflejada en la llegada a Valencia en $1814^{138}$ del Himno al Inmortal Wellin-

\footnotetext{
${ }^{124}$ María José Corredor Álvarez: "Aportaciones musicales de la Guerra de la Independencia a un nuevo género nacional: la zarzuela", Cuadernos de Música Iberoamericana, 2-3, 1996-1997, pp. 54-55, citado en M. Gembero-Ustárroz: "La música en España e Hispanoamérica... ”, p. 197.

${ }^{125}$ Diario de Madrid, n. ${ }^{\circ}$ 31, 7-9-1808, p. 171.

${ }^{126}$ E-Mn: [Música para voz y piano], MP/1138(2).

${ }^{127}$ El Lord Wellington triunfante, Batalla de Arapiles o destrucción de Marmont, Valencia, Imprenta de Estevan, 1813.

${ }^{128}$ En E-Mn se conservan tres versiones con el mismo texto y música para voz y piano en un típico 6/8, Allegretto, en Re mayor. E-Mn: Canción patriótica de los Arapiles: para forte piano, MC/5307/30 (http://bdh.bne.es/bnesearch/detalle/bdh0000135313, consulta 27-10-2020); Coplas de la Batalla de Arapiles: con acompañamto. de piano-forte, R/62515 (http://bdh.bne.es/bnesearch/detalle/ bdh0000085688, consulta 27-10-2020); Coplas con Acomp ${ }^{\text {to }}$. de Forte Piano de la Batalla de los Arapiles, MC/4837/71 (http://bdh.bne.es/bnesearch/detalle/bdh0000022864, consulta 28-12-2019).

129 B. Jeffery: España de la guerra..., p. 262.

130 E-Mn: MC/5307/30, Canción de Arapiles ("Velinton en Arapiles") (http://bdh.bne.es/bnesearch/ detalle/bdh0000135313, consulta 27-10-2020).

${ }^{131}$ B. Jeffery: España de la guerra..., p. 331.

132 Diario de Madrid, n. ${ }^{\circ} 299$, 28-10-1813, p. 515.

${ }^{133}$ Ibid., n. ${ }^{\circ} 233,20-8-1813$, p. 232 y n. ${ }^{\circ} 234,21-8-1813$, p. 236.

${ }^{134}$ Emilio Cotarelo y Mori: Isidoro Maiquez y el teatro de su tiempo, Madrid, José Perales y Martínez, 1902, pp. 352, 758.

${ }^{135}$ Diario de Valencia, n. ${ }^{\circ}$ 6, 6-1-1808, p. 24.

${ }^{136}$ Ibid., n. ${ }^{\circ} 22,22-10-1809$, p. 88.

${ }^{137}$ C. Díez: "Teatro, canciones e himnos...", p. 13.

${ }^{138}$ Diario de Valencia, n. ${ }^{\circ}$ 96, 06-4-1814, p. 278.
} 
gton cuyo texto aparecía en la prensa gaditana en $1812^{139}$ y su música en la madrileña en $1813^{140}$. Sus versos se corresponden con los de una partitura que se conserva en un álbum más tardío para piano y voz (ca. 1830-1855) adquirido en 2009 por la Biblioteca Nacional de España ${ }^{141}$, así como con un texto conservado en la Colección Documental del Fraile ${ }^{142}$.

En lo que respecta a los himnos, marchas y canciones patrióticas de contenido alegórico o en forma de arenga, a Valencia llegaron numerosos ejemplos de las piezas más populares que se cantaron en los teatros de la península y que se comercializaron en música para voz y acompañamiento de pianoforte y guitarra. La Canción que se canta en la Comedia de los Patriotas de Aragón, presente en varios anuncios en 1808 (cuadro 1), se refería a la canción o marcha con coro ("A las armas corred, patriotas") que se cantaba durante dicha comedia -escrita por Gaspar Zavala y Zamora (1762-¿1813?)- y se representaba por entonces en el madrileño Teatro del Príncipe con el propósito de recaudar donaciones destinadas a paliar el maltrecho estado del ejército de Aragón ${ }^{143}$. La Marcha dedicada á nuestras tropas, también de 1808, tiene un paralelo evidente con la Marcha de nuestros exercitos contra los franceses que se encuentra en una popular colección de canciones patrióticas impresa en Cádiz ${ }^{144}$.

Por último, probablemente tanto la Canción del General Cuesta ${ }^{145}$ como la dedicada a Los vencedores de la Patria, comercializadas por Cabrerizo en 1809 (cuadro 3), fueron las piezas con texto de Juan Bautista Arriaza cuyos títulos se asentaron finalmente como Los defensores de la Patria ("Vivir en cadenas") -la

\footnotetext{
${ }^{139}$ Francisco Bravo Liñán: La poesía en la prensa del Cádiz de las Cortes, 1810-1813, Cádiz, Fundación Municipal de Cultura, 2005, pp. 344 y ss.

${ }^{140}$ Como una "canción patriótica con acompañamiento de piano". Diario de Madrid, n. ${ }^{\circ}$ 173, 22-61813, p. 694.

${ }_{141}$ E-Mn: MP/3172/16 (http://bdh.bne.es/bnesearch/detalle/bdh0000159835, consulta 27-102020).

142 Véase P. Capdepón: "La música madrileña...", p. 134; B. Jeffery: España de la guerra..., p. 326.

${ }^{143}$ Tanto la armonía como el ritmo de esta canción eran más complejos que los habituales en este género. M. J. Corredor Álvarez: "Aportaciones musicales...", pp. 54-55, citado en María Gembero-Ustárroz: "La música en España e Hispanoamérica...", p. 197.

${ }^{144}$ Colección de canciones patrióticas hechas en demostracion de la lealtad española: en que se incluye también la de la nacion inglesa titulada El God Sev de King, impresa en Cádiz: por D. Nicolás Gómez de Requena, [1809] (http://bdh.bne.es/bnesearch/detalle/bdh0000147503, consulta 27-10-2020).

${ }^{145}$ El general Gregorio García de la Cuesta (1741-1811), tras algunas sonoras derrotas al mando del mal llamado "ejército de Castilla", pudo conseguir derrotar a los franceses al mando del reconstruido "ejército de Extremadura", aunque más tarde fue derrotado en la batalla de Medellín (Badajoz, 28-3-1809).
} 
cual transcribió también Francisco Ximeno en 1810 para Pascuala de Pedro-y el Himno de la Victoria ("Venid, vencedores"), convirtiéndose en dos de los himnos de arenga de mayor difusión y fama en el periodo estudiado ${ }^{146}$.

\section{Conclusiones}

El análisis de los datos aportados permite colegir una serie de reflexiones en torno a la llegada y difusión de la música patriótica en el entorno urbano de la ciudad de Valencia. En primer lugar, la penetración del material musical pudo haberse realizado mediante vías de distribución desde la capital ya en otoño de 1808, con lotes de partituras paralelos a otros que se habían anunciado en librerías de Madrid entre tres semanas y dos meses antes. Con el traslado de los centros de poder marcados por el desplazamiento de la Junta Suprema Central hacia Andalucía, al ser ocupada la capital, las obras que llegaron a Valencia se comenzaron a adscribir en origen a otras ciudades como Sevilla y, especialmente, Cádiz, uno de los "mayores focos de producción del repertorio patriótico" 147 . Por otra parte, el volumen de oferta de estos lotes de partituras siguió un patrón demarcado por los acontecimientos bélicos vividos en la ciudad. Así pues, se han podido documentar dos picos en el volumen de la publicidad de estas obras: 1808 y 1810, motivados probablemente por sendos éxitos de la ciudad en los respectivos asedios acontecidos en dichas fechas (gráfico 1).

El empleo por parte de los establecimientos de copistas que adaptaron los títulos para guitarra o pianoforte muestra el alcance de esta música en distintos estratos sociales. Su uso al pianoforte en la esfera privada de las clases acomodadas tiene un claro exponente en la partitura manuscrita de Los defensores de la Patria que Francisco Ximeno transcribió en 1810 para su alumna Pascuala de Pedro, joven hermana del marqués de San José.

El sistema local empleó a copistas y profesores como Josef Francisco Acuña para poder realizar arreglos y musicar textos como el de Fuego $y$ sangre, españoles, generando un pequeño mercado productor de copias y ediciones manuscritas de canciones patrióticas a partir de 1810 que se truncó con el bloqueo francés de la ciudad en 1811 y la huida de sus pro-

${ }^{146}$ Las primeras músicas de ambas piezas fueron compuestas por el guitarrista Fernando Sor (17781839). El Himno de la Victoria, además, recibió música de Murguía y Longarini (E-Mn: MC/5307/16). La canción Los defensores de la Patria había sido compuesta en 1809 para levantar el ánimo tras la derrota del general Cuesta en Extremadura. Estas dos canciones aparecieron posteriormente recopiladas y editadas en Londres por Arriaza en 1810. Juan Bautista de Arriaza: Poesías patrióticas de Dn. J. B. de Arriaza. Reimpresas a solicitud de algunos patriotas españoles residentes en Londres, Londres, T. Bensley, 1810 (http:// bdh.bne.es/bnesearch/detalle/bdh0000022847, consulta 27-10-2020).

${ }^{147}$ C. Díez: "Teatro, canciones e himnos...", p. 25. 
tagonistas a Mallorca. A pesar de ello, Valencia recibió un volumen considerable y variado de obras producidas en todas las etapas del conflicto: música de inspiración revolucionaria y bélica, marchas militares, himnos laudatorios e himnos o canciones patrióticas, muchas de ellas pertenecientes a los títulos más célebres del periodo, aunque con algunas omisiones significativas ${ }^{148}$. La profundización en el estudio de esta literatura, así como la localización y recuperación de ejemplares de esta música constituyen un reto abierto a futuras investigaciones.

Recibido: 30-1-2020

Aceptado: 26-6-2020

${ }^{148}$ Por ejemplo, no se comercializaron en prensa canciones de gran repercusión en el período, como España de la guerra o Españoles, la patria oprimida; así como ninguna propia del bando afrancesado durante la ocupación. 